\title{
Risk Factors of Acute Respiratory Infections in Children under Five Years Attending the Fishtail Hospital, Pokhara, Nepal
}

\author{
Koirala $\mathbf{R}$ \\ Teaching Assistant, Institute of Medicine, Pokhara Nursing Campus, Ramghat, Pokhara, Nepal
}

\begin{abstract}
Introduction: Acute Respiratory Infection (ARI) is one of the leading causes of morbidity and mortality in under five-year children. Risk factors include age, sex, socio-economic status, indoor air pollution, passive smoking, lack of basic health services, and lack of awareness. In this study, we aimed to determine the associated risk factors of ARI in children under five-years of age.
\end{abstract}

Methods: We carried out a hospital-based descriptive cross-sectional study in the peak period of of November 2017 to February 2018. The study was conducted in Fishtail Hospital and Research Center (FHRC), Pokhara, Nepal. Non probability, purposive sampling technique was used and a structural interview was taken for data collection. The tool comprised of two main parts. Part I- questions related to sociodemographic variables of mother and baby. Part II- questions related to risk factors of ARI. The collected data was analyzed using Statistical Package for Social Science (SPSS) software, version 16. The Chi Square statistic is used for testing relationships between categorical variables.

Results: In total of 302 children visited to FHRC with the symptoms of ARI, only 188 (63\%) were diagnosed as ARI. The most common symptoms were fever $(42.2 \%)$, cough $(35.7 \%)$, running nose $(34.1 \%)$, difficulty in breathing (28.5\%) and chest in drawing (11.6\%). The age of children with ARI ranged from one to sixty month with the mean age of $21.46 \pm 13.52$. Among 188 children, $51 \%$ were males whereas $49 \%$ were females. There were no statistically differences of children weight at birth among ARI. Our results revealed environmental and social factors associated with ARI.

Ms Reetu Koirala

Teaching Assistant

Institute of Medicine

Pokhara Nursing Campus

Ramghat, Pokhara, Nepal

Email: reetu.koirala@gmail.com

\section{INTRODUCTION}

Acute Respiratory Infection (ARI) is an acute infection of any part of the respiratory tract infection and related structures including paranasal sinuses, middle ear and pleural cavity. ${ }^{1}$ ARI is one of the leading causes of morbidity and mortality in under five-year children. It kills more children than any other illness more than AIDS, malaria and measles combined accounting for $19 \%$ of all under-five deaths. ${ }^{2}$ It is estimated that Bangladesh, India, Indonesia and Nepal together account for $40 \%$ of the 
global ARI mortality. About $90 \%$ of the ARI deaths is due to pneumonia which is usually bacterial in origin. ${ }^{3}$ ARI is one of the commonest causes of under-five childhood morbidity and mortality in Nepal. In fiscal year 2071/72 B.S (2014/15 AD) a total of 2,208,221 ARI cases have been reported. The total new cases of ARI were $783 / 1000$ among which $155 / 1000$ deaths were reported. ${ }^{4} \mathrm{~A}$ hospital based survey conducted by Shrestha $\mathrm{YB}^{5}$ in Kanti Children Hospital, Kathmandu showed that (40.01\%) of hospital admissions were due to ARI. Among them pneumonia comprised (58.84\%), upper respiratory infections (13.2\%) and bronchitis and bronchiolitis (5.96\%). Among ARI cases, $85 \%$ patients were under five and only $15 \%$ were above five years.

Despite the burden of acute respiratory infection on morbidity and mortality in under five year children, there is limited data on risk factors of ARI to evaluate the problem, especially in the region of western part of Nepal. Several risk factors have been associated with ARI which includes age, sex, socio-economic status, indoor air pollution, passive smoking, immune system defects, lack of basic health services, lack of awareness and overuse and misuse of antibiotics. ${ }^{6,7}$ However, most of these risk factors are preventable ${ }^{8}$, but not been documented in many regions of Nepal. This study therefore aimed to determine the associated risk factors among children under five-years of age with ARI.

\section{METHODS}

\section{Study design and setting}

This was a hospital-based descriptive cross-sectional analytic study carried out in the peak period of the dry season from November 2017 to February 2018. The study was conducted in Fishtail Hospital and Research Center, Gairapatan-4, Pokhara, Nepal. Pokhara, the capital city of the Gandaki state is situated in the Western region of Nepal. Fishtail Hospital is one of the leading private hospital having 100 beds with multisectoral facilities. Its main catchment area includes Kaski, Syanja, Parbat, Tanahun, Baglung and Lamjung districts. The participants in this study included all the mothers having under fiveyear children attending Pediatric OPD with their child having symptoms of ARI. Pediatrician diagnosed cases meeting Integrated Management of Childhood Illness (IMCI) criteria were confirmed as cases of ARI.

\section{Sampling}

Non probability, purposive sampling technique was used for this study. Interview were taken to those mothers whose babies are under five years old and were willing to participate in the study. Mothers who were not willing to participate or not providing complete information were excluded in the study.

\section{Research Instrumentation}

A structured interview schedule was used for data collection. The instrument was based on objectives as well as review of literature in order to collect information in depth. The consultation with concerned expert from nursing peers, colleagues and with pediatric consultants was done for required information. The tool consisted of two main parts. Part I- questions related to sociodemographic variables of mother and baby. Part IIquestion related to risk factors of ARI. The content validity of the instrument was established by performing intense study in the related area, seeking the opinion of experts, and peers. Pretesting of the instrument was done in $10 \%$ of total population of under five-year age children in Pediatric OPD of FHRC. Revision and necessary modification such as using simple words, sequential arrangements of questions etc. were done on the basis of pretest. The instrument was translated into Nepali version.

\section{Data Collection and analysis}

After obtaining the confirmation letter from the concerned authorities of Tribhuvan university, Institute of Medicine (TU, IOM) Pokhara Campus, the proposal was forwarded and got approved from The Ministry of Social Development, Research Department, Gandaki, province. The purpose and objectives of the study were explained to the respondent and verbal consent was obtained.

The data was analyzed on the basis of research objectives. The collected data was checked and organized for accuracy and completeness. Data edited, coded and analyzed on basis of research study using Statistical Package for Social Science (SPSS) software, version 16. Data was analyzed using descriptive statistics (mean, frequency, percentage, standard deviation) and inferential statistics (Chi-square test).

\section{RESULTS}

A total of 361 children visited to the FHRC during the study period were selected for the study. Among them 
24 children were under one month of age and 27 parents did not give consent whereas eight questionnaires had incomplete information. In total of 302 children visited to FHRC with the symptoms of ARI are participated in the study. The most common symptoms are fever (42.2\%), cough (35.7\%), running nose (34.1\%), difficulty in breathing $(28.5 \%)$ and chest in drawing were $11.6 \%$. After Pediatrician consultation, among 302 children, only 188 children were diagnosed having ARI. So, the prevalence of ARI under five-year children in FHRC was $62.3 \%$ (188/ 302). Integrated Management of Childhood Illness (IMCI) classifies ARI into mild, moderate and severe pneumonia. ${ }^{9}$ Using IMCI guidelines, a total of $48.9 \%(92 / 188)$ were having mild ARI (no pneumonia),34.6\% (65/188) moderate and $16.5 \%(31 / 188)$ were severe ARI (Severe pneumonia) (Fig 1).

The age of participated children with ARI ranges from one to sixty month with the mean age of $21.46 \pm 13.52$. Out of the 188 children, 96 (51\%) were males whereas 92 (49\%) were females. The highest percentage of ARI, 31.4\%, was among 1 to 12 months children, followed by $26.6 \%$ among 13 to 24 months and the least $9 \%$ was among 49 to 60-months children. The children belong to the different ethnicity, with highest percentage was from Brahmin (28.7\%) followed by Janajati (27.2\%), Chhetri (25.0\%), and Dalit (19.1\%). Most of the children are by birth Hindu (89.8) and few belong to other religion family, Buddhist (2.1\%), Christian (4.5) and Muslim (3.7\%). Mother's age, education, occupation, along with types of family and economical status, were presented at Table 1.

The findings of the study revealed maximum number of the mothers belonged to more than 25 years which accounts (54.2\%) of total mothers. Majority of (64.9\%) mothers were housewife compare to service holder mothers of children (35.1\%). Most of the mothers are literate (86.2\%). The highest number, $28.7 \%$ of the mothers were from Brahmin ethnic group, Janajati (27.2\%) and Chettri (25.0\%) followed by Dalit (19.1\%). Majority (89.8\%) of mothers of under five-year children belonged to Hindu religion. The greater number (77.1\%) of mothers had adequate economic status. Regarding their living style only $47.9 \%$ mothers were from joint family.

Clinical factors associated with ARI were presented at Table 2. Most of the children were normal weight at birth $(81.4 \%)$ and $13.8 \%$ children were of low weight birth and $4.8 \%$ were overweight at birth (Data not shown). There were no statistically differences of children weight at birth among ARI and non ARI children group. Similarly, colostrum given at birth, breast feeding and immunization status has not elucidated any statistically differences among ARI and non ARI children group. However, the nutritional status has influences in ARI.

Our results revealed environmental and social factors associated with ARI. Exposed to wood smoke had high chances to get ARI ( $p=0.001)$. Whereas passive smoker had no significantly chances to get ARI. In this study, we did not find statistically significant for the chances of ARI of the factors like mother's education, knowledge on ARI and day care attendance. However, we found factors like mosquito coil use in the house, caregiver's cooking method, history of contact with ARI person, had high chances to ARI (Table 3).

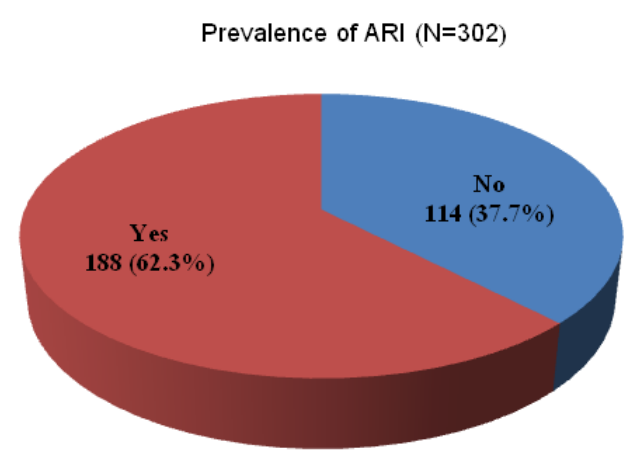

Fig 1A: Prevalence of ARI in FHRC

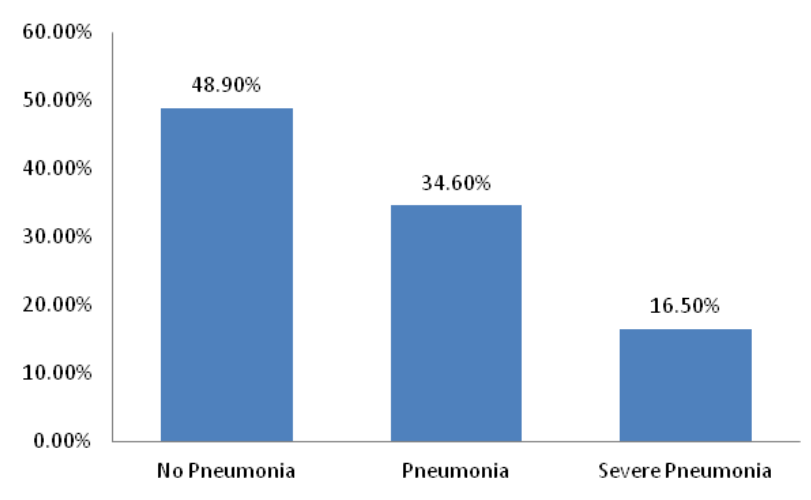

Fig 1B: Proportion of ARI using IMCI definition in children less than five years 
Table 1: Socio-demographic characteristics of respondents

\begin{tabular}{|c|c|c|}
\hline Variables & Frequency $(\mathrm{N}=188)$ & Percentage (\%) \\
\hline \multicolumn{3}{|l|}{ Gender of children } \\
\hline Males & 96 & $51.0 \%$ \\
\hline Females & 92 & $49.0 \%$ \\
\hline \multicolumn{3}{|l|}{ Children age in months } \\
\hline $1-12$ months & 59 & $31.4 \%$ \\
\hline 13-24 months & 50 & $26.6 \%$ \\
\hline $25-36$ months & 37 & $19.7 \%$ \\
\hline $37-48$ months & 25 & $13.3 \%$ \\
\hline $49-60$ months & 17 & $9.0 \%$ \\
\hline \multicolumn{3}{|l|}{ Mother age } \\
\hline More than 25 & 102 & $54.2 \%$ \\
\hline Less than 25 & 86 & $45.7 \%$ \\
\hline \multicolumn{3}{|l|}{ Mother education } \\
\hline Literate & 164 & $86.2 \%$ \\
\hline Illiterate & 24 & $12.8 \%$ \\
\hline \multicolumn{3}{|l|}{ Mother occupation } \\
\hline Housewife & 122 & $64.9 \%$ \\
\hline Service holder & 66 & $35.1 \%$ \\
\hline \multicolumn{3}{|l|}{ Economic Status } \\
\hline Adequate & 145 & $77.1 \%$ \\
\hline Inadequate & 43 & $22.9 \%$ \\
\hline \multicolumn{3}{|l|}{ Types of Family } \\
\hline Nuclear & 98 & $52.1 \%$ \\
\hline Joint & 90 & $47.9 \%$ \\
\hline \multicolumn{3}{|l|}{ Ethnicity } \\
\hline Brahmin & 54 & $28.7 \%$ \\
\hline Chettri & 47 & $25.0 \%$ \\
\hline Janajati & 51 & $27.2 \%$ \\
\hline Dalit & 36 & $19.1 \%$ \\
\hline \multicolumn{3}{|l|}{ Religion } \\
\hline Hindu & 169 & $89.8 \%$ \\
\hline Buddhist & 4 & $2.1 \%$ \\
\hline Christian & 8 & $4.5 \%$ \\
\hline Muslim & 7 & $3.7 \%$ \\
\hline
\end{tabular}

Table 2: Clinical factors associated with ARI

\begin{tabular}{|c|c|c|c|}
\hline Factors & Total $(\mathrm{N}=302)$ & ARI $(\mathrm{N}=188)$ & $p$ value \\
\hline \multicolumn{4}{|l|}{ Weight at Birth } \\
\hline Normal & 248 & $153(61.7 \%)$ & \multirow{3}{*}{0.19} \\
\hline Low birth weight $(<2.5 \mathrm{~kg})$ & 43 & $26(60.4 \%)$ & \\
\hline Over weight (>4 kg) & 11 & $9(81.8 \%)$ & \\
\hline \multicolumn{4}{|l|}{ Colostrum given at birth } \\
\hline Yes & 268 & $169(89.9 \%)$ & \\
\hline No & 34 & $19(10.1 \%)$ & 0.26 \\
\hline \multicolumn{4}{|l|}{ Breast feeding } \\
\hline Mixed & 221 & $119(53.8 \%)$ & \\
\hline Exclusive & 82 & $69(84.1 \%)$ & 0.15 \\
\hline \multicolumn{4}{|l|}{ Nutritional status } \\
\hline Normal & 286 & $177(61.8 \%)$ & \\
\hline Malnourished & 16 & $11(68.7 \%)$ & 0.003 \\
\hline \multicolumn{4}{|l|}{ Immunization status } \\
\hline Up to date Vaccination & 294 & $183(62.2 \%)$ & \\
\hline No/Incomplete vaccination & 8 & $5(62.5 \%)$ & 0.29 \\
\hline
\end{tabular}

Table 3: Environmental and social factors associated with ARI

\begin{tabular}{|c|c|c|c|}
\hline Factors & Total $\quad(\mathrm{N}=302)$ & ARI ( $N=188)$ & $p$ value \\
\hline \multicolumn{4}{|c|}{ Exposure to wood smoke } \\
\hline Not exposed & 272 & $165(60.6 \%)$ & \\
\hline Exposed & 30 & $23(76.6 \%)$ & 0.001 \\
\hline \multicolumn{4}{|l|}{ Cigarette smoke } \\
\hline No & 285 & $177(62.1 \%)$ & \\
\hline Yes & 17 & $11(64.7 \%)$ & 0.11 \\
\hline \multicolumn{4}{|c|}{ Mosquito Coil use in the house } \\
\hline Mixed & 198 & $106(53.5 \%)$ & \\
\hline Exclusive & 104 & $82(78.8 \%)$ & 0.02 \\
\hline \multicolumn{4}{|c|}{ Caregivers' Cooking Methods } \\
\hline Gas & 272 & $165(60.6 \%)$ & \\
\hline Kerosene stove & 17 & $13(76.45)$ & \\
\hline Firewood & 13 & $10(76.9 \%)$ & 0.005 \\
\hline \multicolumn{4}{|l|}{ Day Care Attendance } \\
\hline No & 258 & $160(62.0 \%)$ & \\
\hline Yes & 44 & $28(63.6 \%)$ & 0.38 \\
\hline \multicolumn{4}{|l|}{ History of contact* ${ }^{*}$} \\
\hline No & 202 & $101(50.0 \%)$ & \\
\hline Yes & 100 & $87(79.8 \%)$ & 0.001 \\
\hline \multicolumn{4}{|c|}{ Mother's level of education } \\
\hline Literature & 262 & $164(62.5 \%)$ & \\
\hline Illiterate & 40 & $24(60 \%)$ & 0.12 \\
\hline \multicolumn{4}{|c|}{ Mother knowledge on ARI } \\
\hline Adequate & 167 & $102(61.1 \%)$ & \\
\hline Inadequate & 135 & $86(63.7 \%)$ & 0.09 \\
\hline
\end{tabular}

* Contact with someone who has a cough

\section{DISCUSSION}

Acute respiratory tract infection (ARI) is regarded as one of the major public health problems and constitutes a major cause of morbidity and mortality among under-five children in the developing countries. ${ }^{10}$ The prevalence of ARI in this study was $62.3 \%$ which is similar to the report by Sikolia et $\mathrm{al}^{11}$ in Kenya with the prevalence rate of $69.7 \%$. A community based study conducted in India by Goel et al found the prevalence of ARI to be $52 \%$, lower compared to our study. ${ }^{12}$ The prevalence of ARI was high in this study is most likely because of the care givers had poor knowledge of ARI, low socioeconomic status and higher level of exposure to risk factors. Using IMCI guidelines, our data revealed 34.6\% moderate ARI (Pneumonia) This is higher than the proportion of pneumonia (17.2\%) in the other study. ${ }^{13}$ This is because the diagnostic criteria of pneumonia according to Integrated Management of Childhood Illnesses (IMCI) guidelines are highly sensitive.${ }^{14}$ Our study revealed that the highest prevalence of ARI was among those below two years of age. Among above two years age, the prevalence decrease is similar to 
a community based study in Australia as there is inverse relationship between the age and prevalence of ARI. ${ }^{15}$ The findings of the study revealed maximum number of the mothers belonged to more than 25 years (54.2\%) with majority of housewife. Most of the mothers are literate (86.2\%) with good economic status. This analysis was done to assess the knowledge of mothers on ARI. The mother's demographic data, economical status and knowledge of ARI may influences the cause of ARI in their children ${ }^{3-5}$ In this study, we identify some related risk factors in children under five year attending FHRC. Nutritional status has shown a risk factor for the cause of ARI. This finding is consistent with a study conducted in Nigeria by Ujunwa et $\mathrm{al}^{6}$ and in india by Rahman et al ${ }^{16}$ where malnutrition was a significant risk factor associated with ARI

Of the environmental and social risk factors identified in our study, exposure to wood smoke, mosquito coil use in the house and history of contact were found to be significant. WHO reported that children exposed to cooking fuels, mosquito coil, increase the risk of developing pneumonia. ${ }^{13,17}$ The community has to be educated on the dangers of wood smoke because it is the main source of cooking fuel in the local communities. Contact with someone who had symptoms of respiratory disease significantly increases the risk of a child to develop ARI. ARIs are communicable diseases transmitted by droplets from infected persons. This is an association that has been found in other studies. ${ }^{13}$ So, the children should be kept away from people affected with respiratory infection, to prevent them from getting infected. Passive cigarette smoking in this study was not found to be a significant risk factor of ARI, which is in contrast to some other study, where passive smoking is a risk for ARI. ${ }^{13}$ This contrast report may be due to the level of exposure to passive smoking. Reducing those risk factors may reduce the cases of ARI in children

\section{Limitations of the study}

This study is a hospital-based study and not all of children with ARIs go to the hospital for medical care so the proportion may not be a true reflection of the community. Therefore, a longitudinal study would better illustrate the effects of the potential risk factors.

\section{CONCLUSION}

The proportion of acute respiratory infections in the
Fishtail Hospital and Research Center (FHRC), Pokhara, Nepal was $62.3 \%$. The risk factors significantly associated with ARI were malnutrition, exposure to wood smoke, mosquito coil use in house and contact with person having ARI. Reducing these conditions will reduce the morbidity and mortality associated with ARI in children.

\section{REFERENCES}

1. Datta P. Textbook of Paediatric Nursing. 2nd ed. New Delhi: Jaypee Brothers Medical Publishers (P) Ltd.; 2013.

2. Wardlaw T, Johanson EW, Hodge M. Pneumonia: The forgotten killer of children: WHO; 2006. p. 1-2.

3. Park K. Textbook of Preventive and Social Medicine. In. Jabalpur: Banarsidas Bhanot Publishers; 2005. p. 141-6.

4. Government of Nepal, Ministry of Health, Department of Health Services. ARI. Annual Report. 2071/72: p. 62.

5. Shrestha YB, Respiratory diseases in Kanti Hospital. Journal of Institute of medicine. 1983;5:119-28.

6. Ujunwa F, Ezeonu C. Risk factors for acute respiratory tract infections in under-five children in Enugu South-East Nigeria. Ann Med Health Sci Res. 2014;4(1):95-9.

7. Prajapati B, Talsania N, Sonaliya K. A study on prevalence of acute respiratory tract infections (ARI) in under-five children in urban and rural communities of Ahmedabad district, Gujarat. Natl J Community Med. 2011;2(2):255-9.

8. Schluger NW, Koppaka R. Lung disease in a global context. A call for public health action. Ann Am Thorac Soc. 2014;11(3):407-16.

9. Patwari AK, Raina N. Integrated Management of Childhood Illness (IMCI): A robust strategy. Indian J Pediatr. 2002;69(1):41-8.

10. Chisti M, Duke T, Robertson C, Ahmed T, Faruque A, Bardhan P, et al. Co-morbidity: exploring the clinical overlap between pneumonia and 
diarrhoea in a hospital in Dhaka, Bangladesh. Ann Trop Paediatr. 2011;31(4):311-9.

11. Sikolia DN, Cherop H, Hussein A, Juma M, Kurui J, Emmanuel E, et al. The prevalence of acute respiratory infections and the associated risk factors: a study of children under five years of age in Kibera Lindi village, Nairobi, Kenya. J Natl Inst Public Health. 2002; 51: 1.

12. Goel K, Ahmad S, Agarwal G, Goel P, Vijay Kumar. A cross sectional study on prevalence of Acute Respiratory Infections (ARI) in under-five children of Meerut District. India J Community Med Health Educ. 2012; 2:176.

13. Tazinya AA, Halle-Ekane GE, Mbuagbaw LT, Abanda M, Atashili J, Obama MT. Risk factors for acute respiratory infections in children under five years attending the Bamenda Regional Hospital in Cameroon. BMC Pulmonary Medicine. BMC Pulm Med. 2018 Jan 16;18(1):7.

14. Patwari AK, Raina N. Integrated Management of Childhood Illness (IMCI): A robust strategy. Indian J Pediatr. 2002;69(1):41-8.

15. Jones LL, Hashim A, McKeever T, Cook DG, Britton J, Leonardi-Bee J. Parental and household smoking and the increased risk of bronchitis, bronchiolitis and other lower respiratory infections in infancy: Systematic review and meta-analysis. Respiratory res. 2011;12(1):5.

16. Rahman MM, Shahidullah M. Risk factors for acute respiratory infections among the slum infants of Dhaka city. Bangladesh Med Res Counc Bull. 2001;27(2):55-62.

17. Yadav S, Khinchi Y, Pan A, Gupta SK, Shah GS, Baral DD, et al. Risk factors for Acute Respiratory Infections in hospitalized under five children in Central Nepal. J Nepal Paediatr Soc. 2013;33(1):3944. 